\title{
Bowel problems and coping strategies in people with multiple sclerosis
}

Christine Norton and Sonya Chelvanayagam

\begin{abstract}
Multiple sclerosis (MS) is a common neurological disease, estimated to affect 100,000 people in the UK. Bowel symptoms are reported to be common in MS, with constipation affecting $29-43 \%$ and faecal incontinence affecting just over $50 \%$. Both have an impact on quality of life. Very little is known about how people with MS manage their bowels and the effectiveness of different interventions. We conducted a 2-part survey of people with MS and bowel problems. MS Society members were invited to participate in an online survey: 155 replied. 47 people additionally filled in a more detailed postal questionnaire. In this selfselected sample, $34 \%$ spend more than 30 minutes a day managing their bowel. Managing bowel function was rated as having an impact equal to mobility difficulties on quality of life. Respondents used a wide range of strategies to manage their bowel but few were rated as very helpful. There is a need for high quality research on all aspects of managing bowel dysfunction in MS in order to improve patients' quality of life.
\end{abstract}

Keywords: Multiple sclerosis, Bowel function, Constipation, Faecal incontinence, Quality of life

Multiple sclerosis (MS) is a common neurological disease, estimated to affect 100000 people in the UK (MS Society, 2009). It is characterized by focal demyelination and plaque formation in the central nervous system. The effects of MS are very variable, depending on the individual's pattern of demyelination. Onset is most usually in the third or fourth decade of life, but first symptoms can occur at any age in adulthood. Early symptoms can be mild, intermittent and ambiguous, and there may be considerable delay between the onset of symptoms and a definitive diagnosis. Several patterns may be distinguished, the three main types being:

- Relapsing-remitting

- Primary progressive

- Secondary progressive.

Bowel symptoms are reported to be common in MS, with constipation affecting $29-43 \%$ and faecal incontinence affecting just over 50\% (Hinds et al, 1990; Hennessey et al, 1999). Upper gut symptoms such as difficulty swallowing are also widespread (Hinds and Wald, 1989). Constipation is reported to pre-date diagnosis in many cases, and may be an early non-specific symptom of the disease (Hinds et al, 1990).

Occasionally, severe constipation is the first presenting symptom of MS (Lawthom et al, 2003). There is a considerable overlap between constipation and faecal incontinence 
(Coggrave et al, 2003; Nordenbo, 1996), with more than $40 \%$ of people with MS reporting one or both, even among those with mild disability (Eidelman and Wald 1990; Chia et al, 1995; Bakke et al, 1996).

Bowel problems have been found to be associated with more severe disability, disease progression, and depression, but not necessarily with gender (Bakke et al, 1996). The bowel problems associated with specific sub-types of MS have not been identified. Bowel dysfunction was reported long ago as the third most significant factor limiting the ability of people with MS to work (Bauer et al, 1965), but no more recent work on the impact of bowel function, or coping methods could be found.

People with MS have been found to have 2-3 times as many admissions to hospital as the non-neurological population for impaction, megacolon, constipation and volvulus, according a survey of 4 million USA hospital admissions (Sonnenberg et al, 1994). Despite this high prevalence, there has been little attention on bowel dysfunction.

One review found that of 18000 publications on MS in the medical literature over 30 years, only 30 focused on bowel problems (Wiesel et al, 2001), mostly focusing on prevalence and defining physiological mechanisms. Practical coping measures for bowel dysfunction has received little attention in people with $\mathrm{MS}$, with a complete absence of intervention studies (Wiesel et al, 2001; Coggrave et al, 2006). Indeed a Cochrane review of neurological bowel management found only 12 randomized controlled trials of management across all neurological conditions.

It is not known if the burden of bowel dysfunction could be improved by targeted interventions, although one small case study has suggested that some problems are reversible (Wiesel et al, 2000).

\section{The survey}

The present survey was triggered by a Multiple Sclerosis (MS) Society member's letter about constipation which was printed in the society's newsletter MS Matters. This letter generated one of the largest postbags ever received by the MS Society (over 100 letters or emails, according to D. Reeves, MS Society). Many people wrote at length about the bowel problems that they experience. This survey aimed to explore the issue in more detail in order to describe the impact bowel dysfunction has on the lives of people with MS, and to identify interventions that MS Society members find helpful that may warrant further investigation.

\section{Methods}

All the letters and emails (with personal identification removed) that were received in response to the letter were read, and a simple thematic analysis was used to identify recurring themes. These were used to formulate questions for the survey.

The questionnaires were then examined by staff of the MS Society, and by people with MS, to ensure that relevant information had been included, and to check the clarity of the questions. Amendments were made to the questions in light of this feedback.

We conducted a two-stage survey: an initial brief online survey (compiled using Survey Monkey ${ }^{\circledR}$ ), and a more comprehensive questionnaire for people who were willing to give 
further details. The latter could be printed off from a computer and completed by hand to be returned by post.

An invitation to participate in the survey appeared in the MS Society newsletter MS Matters, with details of how to access it online. It was specifically aimed at people with MS. The survey was posted on the MS Society website for a period three months following the circulation of the newsletter. Respondents were invited to contact the researchers if they had any queries regarding completion of the questionnaires or the study.

Consent was taken as implied by the choice to participate in the survey. No personal identification of respondents was requested. Ethical approval for this study was granted by Harrow Ethics Research Committee.

\section{Respondents}

One hundred and fifty five people with MS completed the online survey and 47people returned the second print-off questionnaire. There were missing responses to some questions.

\section{Results from the online survey}

Respondents were predominantly female (77\%), with a median age of 50 years (range 1973). They reported all types of MS and a range of mobility (see Table 1). More than twothirds did not feel that their bowel function was affected by a relapse in their MS.

More than $60 \%$ reported constipation and $30 \%$ faecal incontinence, with nearly $20 \%$ experiencing both (Table 2). Other bowel problems were described in free text. The most common was urgency of defecation (8 people), which was often reported to alternate with constipation. Four respondents reported other bowel conditions: Crohn's disease (2) and irritable bowel syndrome (2).

Respondents used the free text section to discuss these symptoms in more depth:

'Difficulty in emptying bowel, the message from the brain not connecting with the sphincter muscles.'

'I often find I can't go to the toilet even though I feel I need to go, and if I leave it too long I will have an urgency problem.'

'Mainly constipation but when I then need to empty my bowel, urgency sometimes leads to 'accidents'.'

Laxatives were the most commonly used and the most helpful bowel management method for constipation. However, respondents used a range of methods to treat constipation, as well as standard methods listed in Table 3

Respondents discussed how certain positions while sitting on the toilet assisted defecation:

'Lean forward on loo then sit upright while pushing, may have to repeat several times.' 
'When seated on the loo, bending as far forward as possible with head down sometimes helps.'

They also reported that development of a regular bowel habit is important. Diet and exercise was found to be helpful, particularly high fibre diet consisting of fruit, vegetables and bran products.

Three respondents found linseed seeds very helpful, and two respondents found yogurt based products helped to maintain a regular bowel habit. It was apparent that respondents experimented with different methods in order to manage their symptoms.

Management methods for faecal incontinence included the use of particular foods or diet, which was reported as the most helpful strategy (Table 4).

Eight respondents reported the need to wear pads especially when leaving home and five respondents reported that they always ensure a toilet is within close proximity:

'Make sure near toilet and don't go out too often.'

Some respondents reported that they would not leave home until after defaecation occurred which meant that they may remain at home all day:

'Try to go to the toilet early in the day so that I can go out and be fairly safe that I won't have any disasters. I do not stray far from a toilet, so although I love the country I rarely go there to walk as I used to.'

It appears from the free text comments that faecal incontinence appeared to have a much more profound effect on quality of life than symptoms of constipation.

Respondents were asked about the effect of their bowel symptoms on their everyday life $(0=$ not at all $-10=$ a great deal). Figure 1 shows the results. The median response was 6 , with the full range of responses used.

\section{Results from posted questionnaire}

Forty seven respondents also printed a PDF of a more detailed questionnaire, which was completed by hand and returned by post.

The age range of the respondents was 28 to 76 years old with the average (mean) age being 58 years. Again the respondents were predominantly female (93.6\%). Obstetric injury due to forceps delivery can cause faecal incontinence so we were keen to elicit if the female respondents had children which may have contributed to development of bowel symptoms. $74 \%$ of women had at least one child and $40 \%$ of the women had experienced a forceps or ventouse-assisted delivery.

The start of MS symptoms ranged from 2 years to 48 years with the mean being 20 years. $23.4 \%$ of respondents stated that bowel symptoms were the first symptoms of MS and $70.2 \%$ stated that bowel problems were linked to relapses in their condition which is a complete contrast to the result reported in the online survey:

'Has been worsening with the progression of MS over time' 
'Never had bowel problems before MS'

'Bowel incontinence with relapse in 2006'

Apart from one, all respondents reported problems with their bladder function. Some had multiple bladder problems (Table 5).

All forty seven respondents reported taking at least one medication (range 1-13, median 3). Forty five listed medications, including anti-depressants, diazepam, analgesia, proton pump inhibitors, and medications for symptoms of bladder and bowel dysfunction.

Respondents were asked about their usual bowel pattern and when their bowel function is 'at its worst'. Many (44.8\%) reported that usually they opened their bowels every other day and only $4.2 \%$ reported opening their bowel several times a day. However, when their bowel function was 'at its worst' the majority of respondents (31.9\%) reported opening their bowels several times a day.

Respondents were asked about faecal incontinence (FI): $38.3 \%$ reported $\mathrm{FI}$ 'most of the time' ( 1 or more episodes a week but not daily). An additional $31.9 \%$ reported one or more episodes of $\mathrm{FI}$ during the past four weeks, making a total of $70.2 \%$ of respondents with $\mathrm{FI}$ at least monthly.

Interestingly, most respondents did not experience difficulty opening their bowels (44.7\%), not needing to strain to assist defecation. However, $42.6 \%$ reported difficulty in completely evacuating their bowels 'some of the time' ( 1 or more episodes during the past four weeks) and $23.4 \%$ reported this occurring 'most of the time' ( 1 or more episodes a week but not daily).

Respondents were asked what methods/strategies they used to manage their symptoms of incontinence. Fourteen respondents either avoided high fibre or ate high fibre foods which they found moderately helpful. Twelve respondents used medication which included beta blockers, bowel irrigation, laxatives and anti-diarrhoeal agents.

Only three respondents reported using complementary therapy (acupuncture, colonic irrigation and reflexology). Pilates was recorded as 'other treatments for faecal incontinence'.

In respect of constipation, 31 respondents took laxatives, 18 used suppositories and eight respondents used enemas with mixed results. Eighteen respondents used digital stimulation to initiate defecation and 16 respondents manually evacuated their bowel. Twenty three patients used abdominal massage. Six patients used reflexology and one of these also used homeopathy and aromatherapy. Other treatments for constipation included high fibre diets, dried and fresh fruit and linseed oil and exercise. Bowel treatment methods which were unsuccessful for some respondents were listed as helpful for other respondents such as linseed oil, Fybogel and suppositories.

Thirteen people needed someone to help them with their bowel management. Family member/partner was the main person who helped (7respondents). Other people reported district nurse (2), paid carer (1) and someone else (2). The two respondents who indicated this category did not state the role of this person. 
Respondents reported that they spent a variable amount of time daily on bowel management (Table 6). Three reported spending 2 hours on their bowel management daily. As demonstrated by Table 7, this had a significant impact on their lifestyle.

Respondents were asked to rate their current bowel function where $0=$ terrible, worst possible, to $10=$ perfect. The median response was 4 (Figure 2). They were also asked to rate, overall, how much bowel function interferes with everyday life, where $0=$ not at all and $10=$ a great deal (Figure 3). The median response was six.

Respondents were then asked to compare bowel function and management of their bowel with other symptoms that people with MS experience (See Table 8). The question sought to elicit if bowel symptoms detrimentally affected quality of life more than other symptoms commonly experienced with MS. Each symptom was scored between $1-10$ where $1=$ least effect and $10=$ worst effect.

\section{Further Information}

At the end of the questionnaire, respondents were provided with a free text section to record further information about their bowel function. Twenty three respondents provided information regarding:

Constipation

'Constipation is the hardest aspect of MS. Have to get up at 6.30am to make my bowels work'

'Constipation due to neuro-muscular problem'

Faecal incontinence

'Bowel problems are immense - little to no control, problem with mobility when needing to rush. Urinary problems totally controlled by ISC + Sheath + Bag. If only there were something similar for bowel problems'

'One of the worst aspects is not knowing when I need to empty my bowels. Try to empty every time I go to the toilet just in case. Sometimes get leakage'

Both faecal incontinence and constipation:

'Have to wait between $7 \& 10$ days between movements. Get cramps 24 hours before emptying bowels which give sense of urgency, have learnt when the cramps get to a certain intensity that it is time to go to the toilet. Straining only causes haemorrhoids and leakage. Fibre makes it worse'

One person stated:

'This is the worst problem with MS'.

\section{Discussion}

This was a purposive sample of people self-identifying as having a problem with their bowel function. We recognize a possible bias in the sample, as only MS Society members with computer access were able to participate (who may or may not be representative of the 
entire MS population). Those who responded are more likely to experience significant bowel dysfunction than those who do not experience the problem.

However, it is apparent that among the range of symptoms experienced by people with MS, both questionnaires demonstrated that bowel dysfunction and bowel management had the greatest negative impact on their quality of life. This was reflected in both their responses to questions and qualitative feedback they provided.

Medication was found to be the most helpful intervention for managing faecal incontinence and constipation, and people were prescribed a range of medication for both bladder and bowel dysfunction. However, people with MS experience a range of different physical and psychological symptoms, and pharmacological interventions for these symptoms can impact on each other, causing further difficulties (Bywater and While, 2006; Crayton and Rossman, 2006). Some respondents highlighted the need for a bowel assessment - Nortvedt et al (2007) stated that symptoms such as bladder, bowel and sexual dysfunction should be discussed at the early states of the disease. Their study discovered that although only a few people have these symptoms as presenting features of MS, people 2-5 years post MS diagnosis reported significant difficulties. Also it appears if people with MS receive higher levels of social support at an earlier stage of their MS they will report significantly better quality of life (McCabe et al, 2009). Social support does not only relate to friends and family but also support from health and social care professionals.

Many people with MS were spending a lot of time (one third more than 30 minutes per day) on bowel function. This has been found in other neurological conditions such as spinal cord injury (Coggrave et al, 2008), where psychological status has been found to be inversely related to length of time spent on bowel management (the longer the time spent on bowel management the worse the individuals psychological status) (Glickman and Kamm, 1996). It was evident that people with MS would try a range of interventions to improve their symptoms, although most reported only limited effectiveness from most interventions used. We did not gather information on previously tried interventions, which had subsequently been abandoned.

\section{Conclusion}

This survey has found that some people with MS experience bowel dysfunction that significantly impacts their life. People use a range of interventions to help manage these symptoms, with varying degrees of success. There is a need for further development and evaluation of bowel interventions to establish effective bowel management strategies.

Generally, people experiencing bowel symptoms feel stigmatized and are reluctant to inform health professionals. If the nurse introduces the topic it can provide an opportunity for the person to express their concerns and ask further questions. It was evident that many of the respondents of this survey would have welcomed this discussion. Nurses need to be aware that discussion and assessment of bowel function is imperative for people with MS.

\section{Acknowledgements}

The authors wish to acknowledge the help and support of the MS Society in particular MS Matters and the Research Network who assisted in the development of the questionnaire and the management of the study 


\section{References}

Bakke A, Myhr K M, Gronning M, Nyland H (1996) Bladder, bowel and sexual dysfunction in patients with multiple sclerosis - a cohort study. Scand J Urol Nephrol Suppl 179 : 61-6

Bauer H J, Firnhaber W, Winkler W (1965) Prognostic criteria in multiple sclerosis. Ann N Y Acad Sci 122: 542-51

Bywater A, While A (2006) Management of bowel dysfunction in people with multiple sclerosis. Br J Community Nurs 11 (8): 333-41

Chia Y W, Fowler C J, Kamm M A, Henry M M, Lemieux M C, Swash M (1995) Prevalence of bowel dysfunction in patients with multiple sclerosis and bladder dysfunction. J Neurol 242 (2):105-108

Coggrave M, Norton C, Wilson-Barnett, J (2008) Management of neurogenic bowel dysfunction in the community after spinal cord injury: a postal survey in the United Kingdom. Spinal Cord 47 (4):323-30

Coggrave M, Wiesel P, Norton C (2006) Management of faecal incontinence and constipation in adults with central neurological diseases. Cochrane Database Syst Rev 19

(2):CD002115

Coggrave M, Wiesel P, Norton C, Brazzelli M (2003) Bowel management for adults with neurological disease or injury. In: The Cochrane Library, Issue 3. John Wiley and Sons Ltd, Chichester

Crayton H J, Rossamn H S (2006) Managing the symptoms of multiple sclerosis: a multimodal approach. Clin Ther 28 (4): 445-60

Glickman S, Kamm M A (1996) Bowel dysfunction in spinal-cord-injury patients. Lancet 347 (9016): 1651-3

Hennessey A, Robertson N P, Swingler R, Compston D A (1999) Urinary, faecal and sexual dysfunction in patients with multiple sclerosis. J Neurol 246 (11): 1027-32

Hinds J P, Eidelman B H, Wald A (1990) Prevalence of bowel dysfunction in multiple sclerosis. A population survey. Gastroenterology 98 (6): 1538-42

Hinds J P, Wald A (1989) Colonic and anorectal dysfunction associated with multiple sclerosis. Am J Gastroenterol 84 (6): 587-95

Lawthom C, Durdey P, Hughes T (2003) Constipation as a presenting symptom. Lancet 362 (9388): 958

McCabe M P, Stokes M, McDonald E (2009) Changes in quality of life and coping among people with multiple sclerosis over a 2 year period. Psychol Health Med 14 (1): 86-96

MS Society (2009) About MS. Available at:

http://www.mssociety.org.uk/about_ms/index.html (accessed 17 January 2010)

Nordenbo A M (1996) Bowel dysfunction in multiple sclerosis. Sexuality \& Disability 14 (1):33-39 
Nortvedt M W, Riise T, Frugård J et al (2007) Prevalence of bladder, bowel and sexual problems among multiple sclerosis patients two to five years after diagnosis. Multiple Sclerosis 13 (1): 106-12

Sonnenberg A, Tsou V T, Muller A D (1994) The 'institutional colon': a frequent colonic dysmotility in psychiatric and neurologic disease. Am J Gastroenterol 89 (1): 62-6

Wiesel P H, Norton C, Roy A J, Storrie J B, Bowers J, Kamm M A (2000) Gut focused behavioural treatment (biofeedback) for constipation and faecal incontinence in multiple sclerosis. J Neurol Neurosurg Psychiatry 69 (2):240-243

Wiesel P, Norton C, Glickman S, Kamm M A (2001): Pathophysiology and management of bowel dysfunction in multiple sclerosis. Eur J Gastroenterol Hepatol 13 (4):441-8

Table 1. Respondents to the internet survey

\begin{tabular}{|l|l|l|}
\hline & Number & Percentage \\
\hline Type of MS & & \\
\hline Relapsing/remitting & 56 & 36.1 \\
\hline Secondary progressive & 47 & 30.3 \\
\hline Primary progressive & 26 & 16.8 \\
\hline Don't know & 26 & 16.8 \\
\hline Mobility & & \\
\hline Completely unaided & 48 & 31 \\
\hline With a stick & 50 & 32.2 \\
\hline With a frame & 12 & 7.7 \\
\hline Need to use a wheelchair & 43 & 27.8 \\
\hline No answer given & 2 & 1.3 \\
\hline Bowel problems linked to relapses in MS & & \\
\hline Yes & 42 & 27.1 \\
\hline No & 109 & 70.3 \\
\hline No answer given & 4 & 2.6 \\
\hline
\end{tabular}

Table 2. Types of bowel problems

\begin{tabular}{|l|l|l|}
\hline Bowel problem & Number & Percentage \\
\hline None & 1 & 0.6 \\
\hline Constipation or difficulty emptying the bowel & 66 & 42.6 \\
\hline Faecal incontinence & 20 & 12.9 \\
\hline Both constipation and faecal incontinence & 29 & 18.7 \\
\hline Other bowel problem & 27 & 17.4 \\
\hline No answer given & 12 & 7.7 \\
\hline
\end{tabular}

Table 3. Bowel management methods for constipation/evacuation difficulties

\begin{tabular}{|l|l|l|l|l|l|}
\hline $\begin{array}{l}\text { Bowel } \\
\text { management method }\end{array}$ & $\begin{array}{l}\text { Number of } \\
\text { Respondents }\end{array}$ & $\begin{array}{l}\text { Not at all } \\
\text { helpful }\end{array}$ & $\begin{array}{l}\text { Slightly } \\
\text { helpful }\end{array}$ & $\begin{array}{l}\text { Moderately } \\
\text { helpful }\end{array}$ & $\begin{array}{l}\text { Very } \\
\text { helpful }\end{array}$ \\
\hline Laxatives & 84 & 12 & 22 & 29 & 21 \\
\hline Suppositories & 38 & 8 & 8 & 9 & 13 \\
\hline Enemas & 19 & 7 & 2 & 2 & 8 \\
\hline Abdominal massage & 42 & 9 & 19 & 7 & 7 \\
\hline
\end{tabular}




\begin{tabular}{|l|l|l|l|l|l|}
\hline Complementary therapy & 15 & 5 & 3 & 2 & 5 \\
\hline Digital stimulation & 38 & 5 & 8 & 16 & 9 \\
\hline Manual evacuation & 30 & 3 & 8 & 9 & 10 \\
\hline
\end{tabular}

Table 4. Bowel management methods for faecal incontinence

\begin{tabular}{|l|l|l|l|l|l|}
\hline $\begin{array}{l}\text { Bowel } \\
\text { management method }\end{array}$ & $\begin{array}{l}\text { Number of } \\
\text { Respondents }\end{array}$ & $\begin{array}{l}\text { Not at all } \\
\text { helpful }\end{array}$ & $\begin{array}{l}\text { Slightly } \\
\text { helpful }\end{array}$ & $\begin{array}{l}\text { Moderately } \\
\text { helpful }\end{array}$ & $\begin{array}{l}\text { Very } \\
\text { helpful }\end{array}$ \\
\hline Particular foods/diet & 44 & 8 & 12 & 15 & 12 \\
\hline Medication & 59 & 10 & 6 & 7 & 9 \\
\hline Complementary therapy & 71 & 10 & 0 & 1 & 1 \\
\hline
\end{tabular}

Table 5. Types of bladder conditions

\begin{tabular}{|l|l|l|}
\hline $\begin{array}{l}\text { Bladder problems (multiple boxes could be } \\
\text { ticked) }\end{array}$ & Number of respondents & Percentage \\
\hline Stress urinary incontinence & 14 & 29.8 \\
\hline Urgency & 33 & 70.2 \\
\hline Urge urinary incontinence & 29 & 61.7 \\
\hline Bed wetting & 5 & 10.6 \\
\hline Difficulty emptying the bladder & 17 & 36.2 \\
\hline Need to use an intermittent catheter & 11 & 23.4 \\
\hline Need to use an indwelling catheter & 7 & 14.9 \\
\hline Need to wear a pad for bladder leakage & 19 & 40.4 \\
\hline $\begin{array}{l}\text { Need to use a collection appliance for bladder } \\
\text { leakage }\end{array}$ & 3 & 6.4 \\
\hline
\end{tabular}

Table 6. Time spent on bowel management daily

\begin{tabular}{|l|l|l|}
\hline Duration & Number of respondents & Percentage \\
\hline Up to 5 minutes & 7 & 14.9 \\
\hline $5-15$ minutes & 13 & 27.6 \\
\hline $16-30$ minutes & 11 & 23.4 \\
\hline $31-60$ minutes & 7 & 14.9 \\
\hline More than 1 hour & 7 & 14.9 \\
\hline No response & 2 & 4.3 \\
\hline
\end{tabular}

Table 7. Bowel management and lifestyle

\begin{tabular}{|l|l|l|l|l|}
\hline Effect on lifestyle & No response & Not at all (\%) & A little (\%) & A lot (\%) \\
\hline $\begin{array}{l}\text { I fit my life around my bowel } \\
\text { management }\end{array}$ & 4 & $4(8.5)$ & $17(36.2)$ & $22(46.8)$ \\
\hline $\begin{array}{l}\text { Bowel management stops me } \\
\text { working outside my home }\end{array}$ & 8 & $22(46.8)$ & $10(21.3)$ & $7(14.9)$ \\
\hline $\begin{array}{l}\text { Managing my bowels } \\
\text { interfereswith personal } \\
\text { relationships }\end{array}$ & 6 & $20(42.5)$ & $14(29.8)$ & $7(14.9)$ \\
\hline $\begin{array}{l}\text { Bowel management stops } \\
\text { me staying away from home }\end{array}$ & 5 & $16(34)$ & $17(36.2)$ & $9(19.1)$ \\
\hline
\end{tabular}




\begin{tabular}{|l|l|l|l|l|}
\hline $\begin{array}{l}\text { My bowel management is a } \\
\text { problem to me }\end{array}$ & 2 & 0 & $17(36.2)$ & $28(59.6)$ \\
\hline $\begin{array}{l}\text { Bowel management } \\
\text { interferes with my social life }\end{array}$ & 3 & $13(27.6)$ & $22(46.8)$ & $9(19.1)$ \\
\hline
\end{tabular}

Table 8. Impact of MS symptoms on quality of life

\begin{tabular}{|l|l|l|l|l|l|l|l|l|l|l|l|l|l|}
\hline MS symptoms & $\mathbf{1}$ & $\mathbf{2}$ & $\mathbf{3}$ & $\mathbf{4}$ & $\mathbf{5}$ & $\mathbf{6}$ & $\mathbf{7}$ & $\mathbf{8}$ & $\mathbf{9}$ & $\mathbf{1 0}$ & $\mathbf{N} / \mathbf{A}$ & $\begin{array}{l}\text { No } \\
\text { response }\end{array}$ & $\begin{array}{l}\text { Median } \\
\text { response }\end{array}$ \\
\hline $\begin{array}{l}\text { Managing my } \\
\text { bladder }\end{array}$ & 4 & 2 & 1 & 3 & 7 & 6 & 3 & 5 & 2 & 7 & 4 & 3 & 6 \\
\hline $\begin{array}{l}\text { Changes in my } \\
\text { sexual function }\end{array}$ & 6 & 4 & 3 & 1 & 4 & 2 & 1 & 1 & 2 & 5 & 16 & 2 & 5 \\
\hline $\begin{array}{l}\text { Changes to } \\
\text { my memory }\end{array}$ & 10 & 4 & 3 & 4 & 5 & 2 & 2 & 3 & 1 & 0 & 10 & 3 & 4 \\
\hline $\begin{array}{l}\text { Changes to } \\
\text { my vision }\end{array}$ & 9 & 1 & 4 & 2 & 5 & 3 & 0 & 3 & 1 & 2 & 15 & 3 & 3 \\
\hline $\begin{array}{l}\text { Difficulty with } \\
\text { mobility }\end{array}$ & 2 & 3 & 1 & 2 & 8 & 4 & 2 & 6 & 7 & 5 & 3 & 3 & 7 \\
\hline $\begin{array}{l}\text { Taking care of } \\
\text { my skin }\end{array}$ & 12 & 3 & 2 & 3 & 2 & 1 & 1 & 1 & 0 & 1 & 18 & 3 & 2 \\
\hline $\begin{array}{l}\text { Managing my } \\
\text { bowel }\end{array}$ & 1 & 2 & 1 & 3 & 4 & 4 & 7 & 7 & 5 & 7 & 3 & 3 & 7 \\
\hline $\begin{array}{l}\text { Living with } \\
\text { chronic pain }\end{array}$ & 9 & 4 & 4 & 0 & 3 & 3 & 2 & 2 & 3 & 5 & 14 & 3 & 3 \\
\hline $\begin{array}{l}\text { Living with } \\
\text { spasticity }\end{array}$ & 6 & 4 & 4 & 3 & 3 & 3 & 2 & 7 & 2 & 1 & 9 & 3 & 5 \\
\hline
\end{tabular}

Figure 1. Reported effect of bowel problems on everyday life

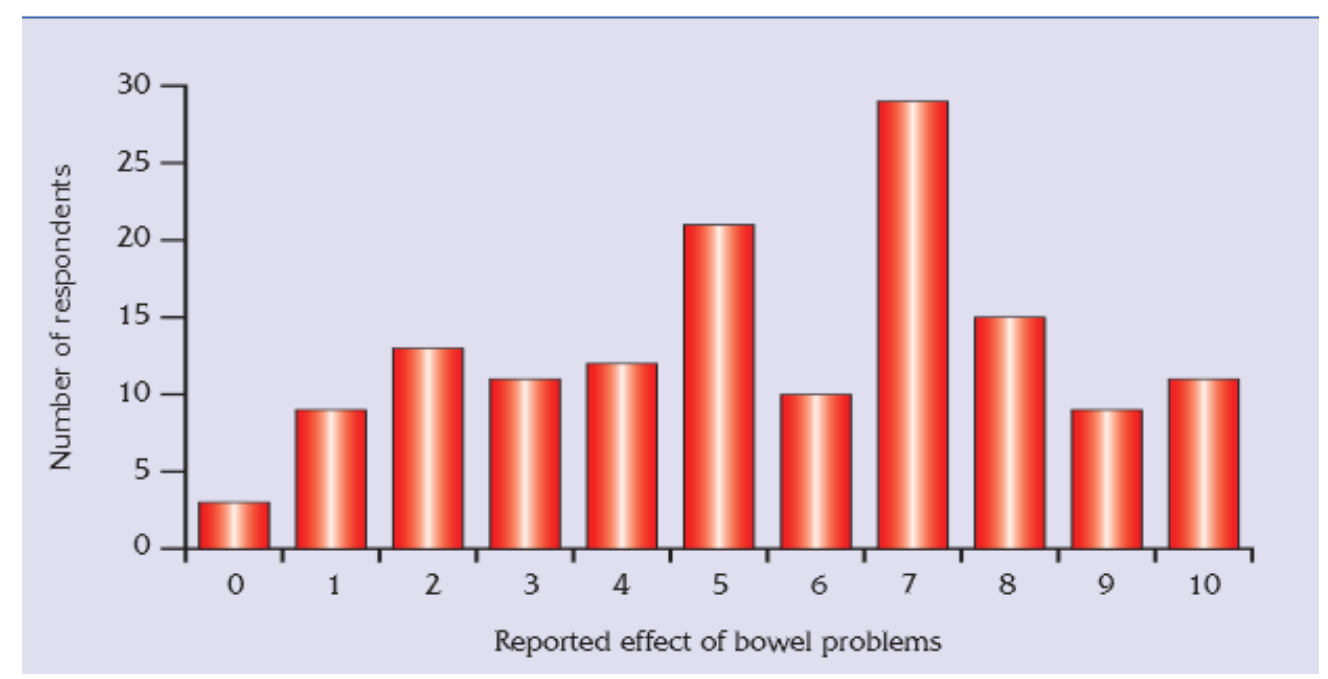

Figure 2. Rating of current bowel function 


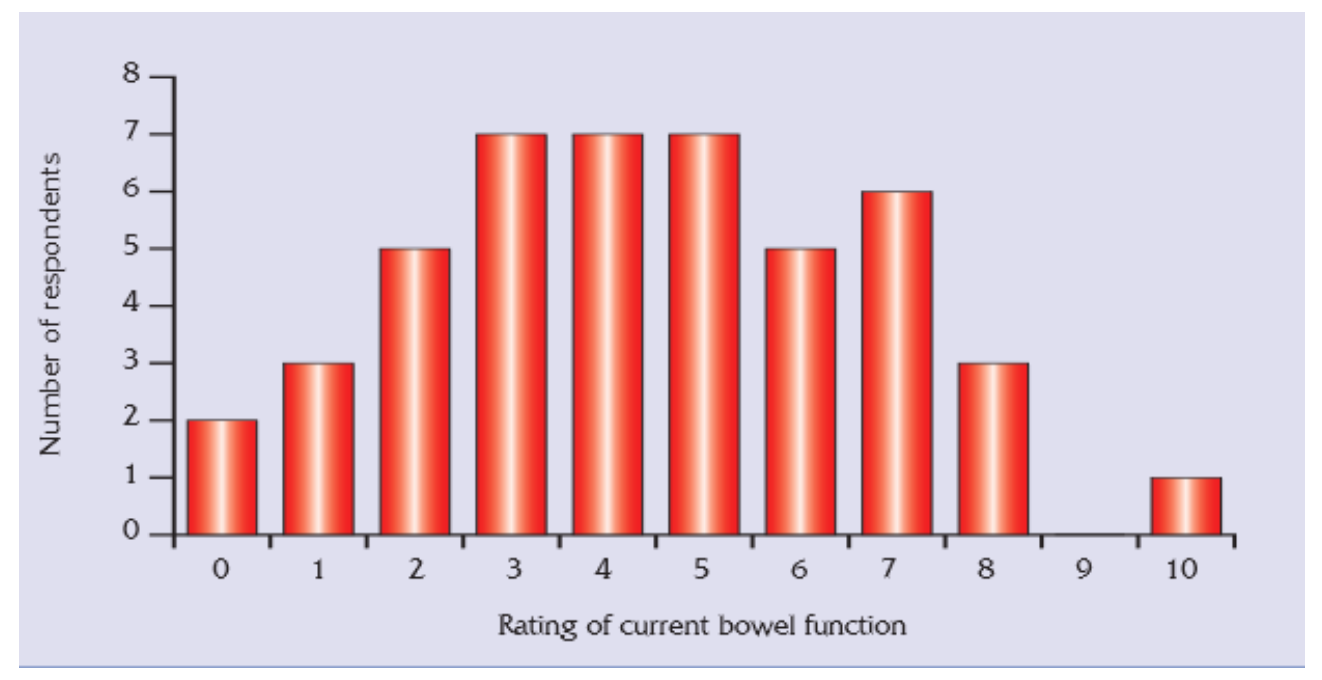

Figure 3. Impact of bowel function on lifestyle

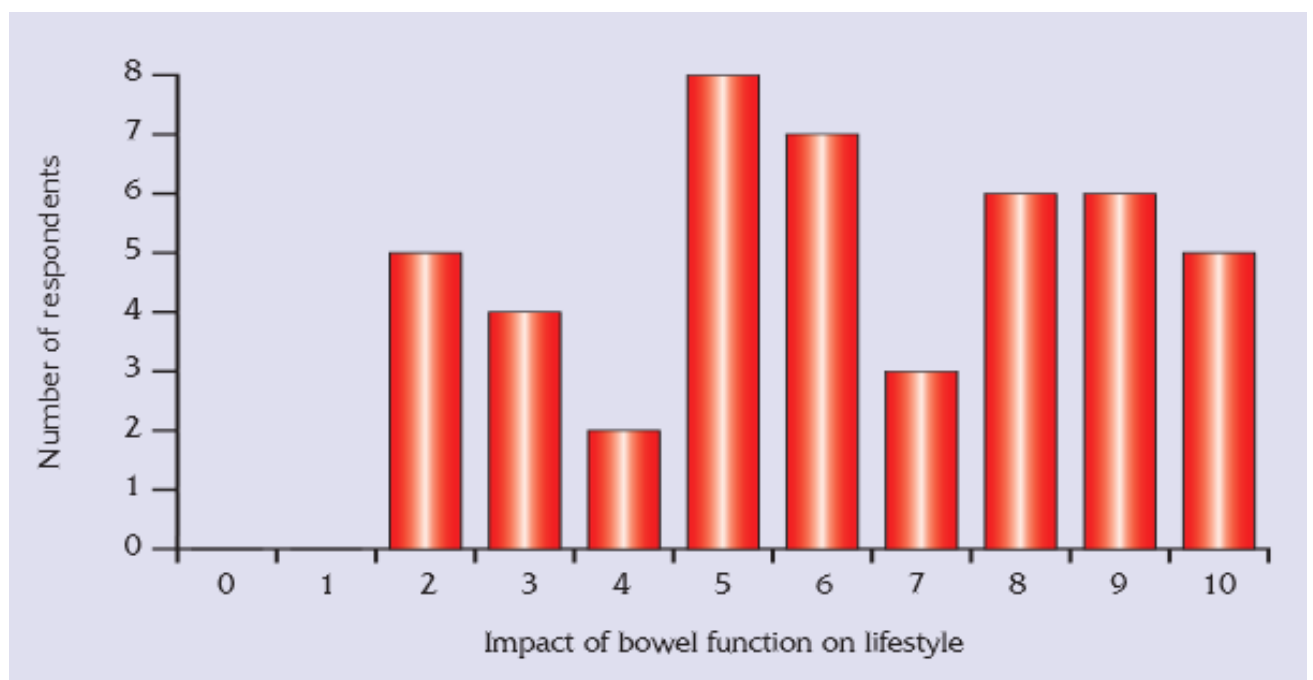

